\title{
Diabetes and exercise
}

\author{
Author: Alistair Lumb ${ }^{A}$
}

Exercise has a beneficial effect on metabolic parameters affecting cardiovascular risk, such as lipids and blood glucose, and is a key component in both the prevention and the management of type 2 diabetes. Glycaemic control improves with both aerobic and resistance exercise in type 2 diabetes, but no glycaemic benefit is seen in type 1 diabetes. This probably results from glucose fluctuations commonly seen with exercise. Low and moderate intensity exercise are generally associated with a fall in blood glucose, and high intensity exercise can be associated with a rise in blood glucose. Trial evidence is suggestive of a reduction in cardiovascular risk with exercise, although evidence from prospective, randomised controlled trials is certainly not conclusive.

\section{Introduction}

A formal definition of the word exercise would be 'physical activity carried out to sustain or improve health or fitness'. Diabetes is a major cause of morbidity and premature mortality in many countries, in particular related to cardiovascular disease. Physical activity and exercise is known to have a beneficial effect on a variety of factors relevant to diabetes and cardiovascular disease, including blood pressure, lipid profiles, endothelial function, body composition and insulin sensitivity. ${ }^{1}$ Exercise is therefore recommended for both the prevention of diabetes and the treatment of people with diabetes. The latest recommendations of the American Diabetes Association are detailed in Box $1 .^{2}$

\section{Exercise in the prevention of type 2 diabetes}

The prevalence of type 2 diabetes mellitus (T2DM) is increasing both nationally in the UK and globally at an alarming rate. ${ }^{3}$ This epidemic is associated with increases in obesity and physical inactivity, so exercise would appear to be a key strategy for reversing this trend.

Interventions involving physical activity have been shown to reduce the risk of developing T2DM by between 47 and 58\% in high-risk groups ${ }^{4-6}$ and this reduction in incidence has been shown to persist for 10 years following the initial intervention. ${ }^{7}$

Author: ${ }^{A}$ consultant diabetologist, Oxford Centre for Diabetes, Endocrinology and Metabolism (OCDEM), Churchill Hospital, Oxford, UK
Box 1. Exercise recommendations for people with diabetes.

Based on the American Diabetes Association Standards for Diabetes Care 2014.

$>$ Adults with diabetes should be advised to perform at least 150 minutes per week of moderate-intensity aerobic physical activity (50-70\% of maximum heart rate), spread over at least 3 days per week with no more than 2 consecutive days without exercise.

In the absence of contraindications, adults with type 2 diabetes should be encouraged to perform resistance training at least twice each week.

Positive lifestyle changes that are made during the intervention period persist during the follow-up period, in particular, significant differences in physical activity can be maintained. ${ }^{8}$ Long-term follow-up in one of these studies has demonstrated a significant reduction in both cardiovascular and all-cause mortality at 23 years. ${ }^{9}$ Other long term follow-up studies have not demonstrated this difference, but they were not powered to detect differences between the groups. ${ }^{10}$ In an attempt to overcome this problem, participants from the Finnish Diabetes Prevention Study (DPS) were compared with a matched group with impaired glucose tolerance from another Finnish study. This comparison demonstrated significantly lower total mortality and cardiovascular risk in the Finnish DPS exercise cohort. $^{11}$

\section{Exercise in the treatment of type 2 diabetes}

Traditionally, exercise advice in T2DM has focused on aerobic activity - the type of lower-intensity activity that can be undertaken for extended periods of time, and that can therefore contribute both to lowering of blood glucose and also to significant increases in energy expenditure which can aid weight loss. More recently, it has been recognised that resistance exercise, which is often anaerobic in nature, can also have significant benefits for those with T2DM. Resistance exercise has acute benefits in terms of insulin sensitivity, and can also contribute to an increase in lean body mass that helps to maintain these benefits. A further benefit of resistance exercise can be to increase functional capacity, which can be particularly important for patients in maintaining their independence. 
Much of the data regarding the effects of exercise on blood glucose in T2DM has come from small studies with short follow-up, and so it has been difficult to compare the relative benefits of aerobic and resistance exercise. A recent metaanalysis demonstrated that structured exercise training was associated with a reduction in glycated haemoglobin (HbAlc) of $0.67 \%$ in people with T2DM, with benefit coming from aerobic or resistance exercise separately and both in combination. ${ }^{12}$ The duration of the structured exercise programmes was also found to be important. Programmes with an exercise duration of greater than 150 minutes per week were associated with an HbAlc reduction of $0.89 \%$, whereas those with duration less than 150 minutes per week were associated with a reduction of $0.36 \%$. Physical activity advice was also associated with a significant reduction in HbAlc, but only in combination with dietary advice.

More recently, there has been considerable interest in high-intensity interval training (HIIT). This consists of very short bursts of very high-intensity exercise interspersed with periods of recovery. Early studies with HIIT in T2DM suggest that it is safe and feasible, and acutely results in a lowering of blood glucose. ${ }^{13,14}$ To date, no studies have looked at the effects of HIIT on HbA1c in people with T2DM, and further research is necessary to evaluate effectiveness of this training in the sub-group of people with T2DM capable of performing it. Standardising interventions may make this evaluation challenging.

Again, a key question is whether improving glycaemic control (and other cardiovascular risk factors such as lipid profile and adiposity ${ }^{15}$ ) confers a reduction in the occurrence and severity of cardiovascular disease. A recent meta-analysis of cohort studies coupled with data from a prospective cohort study have suggested that there is a significant benefit, demonstrating an inverse relationship between physical activity and both cardiovascular disease and all-cause mortality. ${ }^{16}$ By contrast, a randomised controlled trial designed to look at this did not

\section{Key points}

> Exercise is well recognised to reduce the risks of cardiovascular disease and to help improve metabolic profiles.

> Pre-exercise assessment may be needed in those with diabetes who are new to exercise, but moderate exercise is generally safe.

> Both aerobic and resistance exercise are useful in the treatment of type 2 diabetes.

> Moderate intensity exercise is often associated with hypoglycaemia in diabetes.

$>$ High intensity exercise can be associated with hyperglycaemia in diabetes.

KEYWORDS: Exercise, type 1 diabetes, type 2 diabetes, physical activity show any difference in a composite cardiovascular endpoint (consisting of death from cardiovascular causes, nonfatal myocardial infarction, nonfatal stroke and hospitalisation for angina) with an intensive lifestyle intervention when compared with standard diabetes education over 10 years. ${ }^{17}$ However, this may be explained by the fact that differences in cardiovascular risk factors between the two groups did not persist throughout the study, and the use of cardioprotective medications (such as ACE inhibitors, statins and metformin) was lower in the intervention group.

\section{Exercise and type 1 diabetes}

Many people with type 1 diabetes mellitus (T1DM) are keen to take part in sport and exercise, often inspired by famous athletes who have diabetes such as Sir Steve Redgrave. This can be because they are talented sports people, or simply because they wish to maintain a healthy lifestyle. T1DM does not have the same association with obesity and insulin resistance as T2DM, but evidence from patients with T1DM does demonstrate improvements in lipid profile, endothelial function and insulin sensitivity with exercise. ${ }^{18}$ Exercise also theoretically reduces both cardiovascular and all-cause mortality, although as with T2DM, evidence from intervention studies is lacking. Interestingly, improvements in HbAlc are not seen with exercise in T1DM. ${ }^{19}$ There are clear challenges to sport and exercise in diabetes, and fear of hypoglycaemia is the main factor limiting the adoption of a more active lifestyle by people with T1DM. ${ }^{20}$ The often erratic dysglycaemia that can be associated with exercise may well explain why improvements in glycaemic control are not seen in T1DM.

\section{Challenges of exercise with diabetes}

There is often concern about the safety of exercise for patients with diabetes, although for most people, the benefits are likely to outweigh any risks. Guidance on pre-exercise assessment can be found in Table $1 .^{2}$ Managing blood glucose during exercise can also be a challenge, but guidance is available. ${ }^{21}$ A brief summary of common problems and basic strategies is given below. The physiological basis for these problems is summarised in Table 2 .

\section{Hypoglycaemia}

Exercise in diabetes, particularly T1DM, can predispose patients to hypoglycaemia. The most rapid drop in blood glucose usually occurs during aerobic or endurance exercise, when circulating insulin suppresses metabolic fuel production and increases glucose uptake into muscles, but an attenuated drop in blood glucose is also seen with intermittent high-intensity exercise (which is a mixture of both aerobic and anaerobic exercise, characteristic of team sports and children's play). ${ }^{22}$ Hypoglycaemia can also occur after all types of exercise, often overnight, most likely because of a combination of increased insulin sensitivity and the need to replenish depleted energy stores. ${ }^{23}$ An extreme case is hypoglycaemia-associated autonomic failure, where a vicious cycle of recurrent hypoglycaemia develops. This occurs because exercise blunts the endocrine response to hypoglycaemia, but hypoglycaemia also blunts the endocrine 


\section{Table 1. Pre-exercise assessment.}

\begin{tabular}{|c|c|}
\hline \multirow[t]{3}{*}{ Cardiovascular disease } & $\begin{array}{l}\text { Cardiovascular assessment should include a full history for cardiovascular symptoms. Where there is } \\
\text { concern, referral to a cardiologist for further assessment is recommended. }\end{array}$ \\
\hline & $\begin{array}{l}\text { There is no evidence for screening of asymptomatic patients, and adverse events are rare. In these } \\
\text { patients, the most sensible approach is often to start with short periods of low-intensity exercise, and to } \\
\text { increase both the intensity and the duration of exercise bouts slowly. }\end{array}$ \\
\hline & > Cardiovascular assessment is recommended for patients with autonomic neuropathy. \\
\hline \multirow[t]{2}{*}{ Peripheral neuropathy } & $\begin{array}{l}\text { For patients with peripheral neuropathy, it is vital to ensure that appropriate footwear is worn and feet } \\
\text { are examined regularly. }\end{array}$ \\
\hline & $\begin{array}{l}\text { Weight-bearing exercise should be avoided in those with active foot disease and more severe } \\
\text { neuropathy, but moderate intensity walking may not increase the risk of ulceration and improves } \\
\text { outcomes in milder neuropathy. }\end{array}$ \\
\hline Retinopathy & $\begin{array}{l}\text { It may be sensible to avoid vigorous exercise in the context of proliferative (or severe non-proliferative) } \\
\text { retinopathy because of the risk of vitreous haemorrhage or retinal detachment. }\end{array}$ \\
\hline \multirow[t]{2}{*}{ Nephropathy } & $\begin{array}{l}\text { There is no evidence for the need for any specific exercise restriction in patients with diabetic renal } \\
\text { disease. }\end{array}$ \\
\hline & $\begin{array}{l}\text { Importantly, cardiovascular disease is increased in individuals with microalbuminuria or proteinuria, and } \\
\text { so particular consideration needs to be given as to whether such patients should undergo exercise } \\
\text { stress testing before embarking on a regular exercise programme. }\end{array}$ \\
\hline \multirow[t]{2}{*}{ Blood glucose } & $\begin{array}{l}\text { If pre-exercise blood glucose is low (less than } 5.6 \mathrm{mmol} / \mathrm{l}) \text {, then take extra carbohydrate before exercise. } \\
\text { This may not be necessary for high-intensity exercise or for those who are not taking insulin or insulin } \\
\text { secretagogues. }\end{array}$ \\
\hline & $\begin{array}{l}\text { If pre-exercise blood glucose is high, there is a risk of ketosis developing because of the counter- } \\
\text { regulatory hormone response to exercise. Nevertheless, if the individual feels well and is well hydrated } \\
\text { and if ketones are absent, then there is no contraindication to exercise. }\end{array}$ \\
\hline
\end{tabular}

Based on the American Diabetes Association Standards for Diabetes Care 2014.

response to exercise, and in extreme cases can result in significant morbidity. ${ }^{24}$

Strategies to combat hypoglycaemia involve reducing circulating insulin by reducing insulin doses and/or increasing energy intake, usually in the form of carbohydrate before or during exercise. Which strategy is adopted depends on individual goals; for example, if weight loss or weight maintenance is important, then a reduction in insulin dose would be preferable. In T1DM, continuous subcutaneous insulin infusion (also known as insulin pump therapy) offers the opportunity to reduce circulating insulin in a manner that more closely mimics normal physiology.

\section{Table 2. Physiological reactions to exercise.}

\begin{tabular}{|c|c|c|}
\hline & $\begin{array}{l}\text { Moderate intensity } \\
\text { (aerobic/ } \\
\text { endurance) }\end{array}$ & $\begin{array}{l}\text { High intensity } \\
\text { (anaerobic/sprint) }\end{array}$ \\
\hline $\begin{array}{l}\text { Primary metabolic } \\
\text { fuel }\end{array}$ & $\begin{array}{l}\text { Glucose and non- } \\
\text { esterified fatty acids }\end{array}$ & Glucose \\
\hline $\begin{array}{l}\text { Main factor } \\
\text { increasing fuel } \\
\text { production }\end{array}$ & $\begin{array}{l}\text { Change in } \\
\text { glucagon:insulin ratio }\end{array}$ & $\begin{array}{l}14-18 \text {-fold rise in } \\
\text { catecholamines }\end{array}$ \\
\hline Insulin & $\downarrow$ & $\begin{array}{l}\hookrightarrow \text { during exercise } \\
\text { then } \uparrow \text { after }\end{array}$ \\
\hline
\end{tabular}

\section{Hyperglycaemia}

High-intensity or anaerobic exercise can predispose to hyperglycaemia, primarily through the normal metabolic response to exercise of this intensity, which includes a significant rise in catecholamines. ${ }^{25}$ Hyperglycaemia can also be seen after all types of exercise, as metabolic fuel production is driven by changes in levels of circulating hormones. These do not return to normal immediately at the end of exercise, meaning that a rise in blood glucose can be seen after exercise finishes.

There is very limited evidence available on how to avoid hyperglycaemia during or after high-intensity exercise. Advice based on experience has recommended the use of small insulin doses of 1 or 2 units of rapid-acting insulin.

\section{Summary}

Exercise has many health benefits, and these are important in both T1DM and T2DM. It is important to be aware that both hypoglycaemia and hyperglycaemia can occur during exercise, but strategies are available to deal with these challenges.

\section{References}

1 Warburton DE, Nicol CW, Bredin SS. Health benefits of physical activity: the evidence. CMAJ 2006;174:801-9. 
2 American Diabetes Association. Standards of medical care in diabetes - 2014. Diabetes Care 2014;37 Suppl 1:S14-S80.

3 Whiting DR, Guariguata L, Weil C, Shaw J. IDF diabetes atlas: global estimates of the prevalence of diabetes for 2011 and 2030. Diabetes Res Clin Pract 2011;94:311-21.

4 Pan XR, Li GW, Hu YH et al. Effects of diet and exercise in preventing NIDDM in people with impaired glucose tolerance. The Da Qing IGT and Diabetes Study. Diabetes Care 1997;20:537-44.

5 Tuomilehto J, Lindstrom J, Eriksson JG et al. Prevention of type 2 diabetes mellitus by changes in lifestyle among subjects with impaired glucose tolerance. N Engl J Med 2001;344:1343-50.

6 Knowler WC, Barrett-Connor E, Fowler SE et al. Reduction in the incidence of type 2 diabetes with lifestyle intervention or metformin. N Engl J Med 2002;346:393-403.

7 Knowler WC, Fowler SE, Hamman RF et al. 10-year follow-up of diabetes incidence and weight loss in the Diabetes Prevention Program Outcomes Study. Lancet 2009;374:1677-86.

8 Lindstrom J, Peltonen M, Eriksson JG et al. Improved lifestyle and decreased diabetes risk over 13 years: long-term follow-up of the randomised Finnish Diabetes Prevention Study (DPS). Diabetologia 2013;56:284-93.

9 Li G, Zhang P, Wang J et al. Cardiovascular mortality, all-cause mortality, and diabetes incidence after lifestyle intervention for people with impaired glucose tolerance in the Da Qing Diabetes Prevention Study: a 23-year follow-up study. Lancet Diabetes Endocrinol 2014;2:474-80.

10 Lindstrom J, Ilanne-Parikka P, Peltonen M et al. Sustained reduction in the incidence of type 2 diabetes by lifestyle intervention: follow-up of the Finnish Diabetes Prevention Study. Lancet 2006;368:1673-9.

11 Uusitupa M, Peltonen M, Lindstrom J et al. Ten-year mortality and cardiovascular morbidity in the Finnish Diabetes Prevention Study secondary analysis of the randomized trial. PLoS One 2009;4:e5656.

12 Umpierre D, Ribeiro PA, Kramer CK et al. Physical activity advice only or structured exercise training and association with HbAlc levels in type 2 diabetes: a systematic review and meta-analysis. JAMA 2011;305:1790-9.

13 Little JP, Gillen JB, Percival ME et al. Low-volume high-intensity interval training reduces hyperglycemia and increases muscle mitochondrial capacity in patients with type 2 diabetes. J Appl Physiol (1985) 2011;111:1554-60.

14 Terada T, Friesen A, Chahal BS, Bell GJ, McCargar LJ, Boule NG. Feasibility and preliminary efficacy of high intensity interval training in type 2 diabetes. Diabetes Res Clin Pract 2013; 99:120-9.

15 Thomas DE, Elliott EJ, Naughton GA. Exercise for type 2 diabetes mellitus. Cochrane Database Syst Rev 2006;3:CD002968.

16 Sluik D, Buijsse B, Muckelbauer R et al. Physical activity and mortality in individuals with diabetes mellitus: a prospective study and meta-analysis. Arch Intern Med 2012;172:1285-95.

17 Wing RR, Bolin P, Brancati FL et al. Cardiovascular effects of intensive lifestyle intervention in type 2 diabetes. $N$ Engl J Med 2013;369:145-54.

18 Chimen M, Kennedy A, Nirantharakumar K, Pang TT, Andrews R, Narendran P. What are the health benefits of physical activity in type 1 diabetes mellitus? A literature review. Diabetologia 2012;55:542-51.

19 Kennedy A, Nirantharakumar K, Chimen M et al. Does exercise improve glycaemic control in type 1 diabetes? A systematic review and meta-analysis. PLoS One 2013;8:e58861.

20 Brazeau AS, Rabasa-Lhoret R, Strychar I, Mircescu H. Barriers to physical activity among patients with type 1 diabetes. Diabetes Care 2008;31:2108-9.

21 Lumb AN, Gallen IW. Diabetes management for intense exercise. Curr Opin Endocrinol Diabetes Obes 2009;16:150-5.

22 Guelfi KJ, Jones TW, Fournier PA. The decline in blood glucose levels is less with intermittent high-intensity compared with moderate exercise in individuals with type 1 diabetes. Diabetes Care 2005;28:1289-94.

23 McMahon SK, Ferreira LD, Ratnam N et al. Glucose requirements to maintain euglycemia after moderate-intensity afternoon exercise in adolescents with type 1 diabetes are increased in a biphasic manner. J Clin Endocrinol Metab 2007;92:963-8.

24 Graveling AJ, Frier BM. Risks of marathon running and hypoglycaemia in Type 1 diabetes. Diabet Med 2010;27:585-8.

25 Marliss EB, Vranic M. Intense exercise has unique effects on both insulin release and its roles in glucoregulation: implications for diabetes. Diabetes 2002;51 Suppl 1:S271-S283.

Address for correspondence: Dr A Lumb, Oxford Centre for Diabetes, Endocrinology and Metabolism (OCDEM), Churchill Hospital, Oxford OX3 7LE, UK. Email: alistair.lumb@nhs.net 